\title{
Technology of Natural Biocorrectors from Seafood Processing Waste
}

\author{
V.D. Bogdanov ${ }^{1 *}$, A.A. Simdyankin ${ }^{1}$, and A.V. Pankina ${ }^{1}$ \\ ${ }^{1}$ Far Eastern State Technical Fisheries University, Engineering Disciplines Department, 52 B \\ Lugovaya Str., Vladivostok 690087, Russia
}

\begin{abstract}
Biocorrectors are dry concentrates from natural raw sources with high nutritional value due to the high content of important chemical components of food, including essential, minor, and biologically active nutrients. The raw material for the production of natural biocorrectors can be waste from cutting the fish and animal products. It is promising to use the skin of an octopus, the weight of which during cutting is up to $37 \%$ of the weight of raw materials, Pacific herring milt, which is formed during cutting in an amount of up to $12.4 \%$ of the weight of raw materials, and bivalve mantle mollusk of Primorsky scallop, accounting for about $10 \%$ of its mass. The goal of the research is to obtain dry food concentrates from seafood waste that exhibit functional properties. To preserve and form the specific properties of finished products, namely high biological value, digestibility, organoleptic indicators of concentrates, low-processing temperatures (cryotechnology) were used, which maximally preserved the composition, structure and other natural properties of raw materials. The dry seafood concentrates obtained by cryogenic technology exhibit high functionality and can be used as biocorrectors of food in order to impart high nutritional and biological value to it due to the balance of micro- and macronutrients.
\end{abstract}

\section{Introduction}

Modern research and development are aimed at creating the technologies for concentrates of natural products from raw materials containing essential, minor, and biologically active food substances. Concentrates are used as a basis for obtaining a variety of instant products or food biocorrectors in order to give it a balance of micro- and macronutrients, high quality and biological value.

In the fishing industry, promising species can be both underutilized raw materials and food waste from cutting the valuable commercial aquatic organisms under their main processing [1,2]. First of all, when choosing the raw materials, it is taken into account that fish and seafood are the source of complete, easily digestible protein, polyunsaturated fatty acids, including the $\omega-3$ and $\omega-6$ kinds, macro- and microelements and can be classified as natural functional nutritional products.

The main direction of using the waste from cutting the fish and seafood is associated with the production of a variety of feed products, primarily feed flour. Depending on the type of

* Corresponding author: bogdanovvd@dgtru.ru 
raw materials and technical equipment of enterprises, as a rule, the following methods of waste treatment are used: chemical or enzymatic hydrolysis, hydrothermal, barothermal and enzymatic-hydrothermal effects on raw materials $[3,4,5,6]$. Products obtained from secondary raw materials, as a rule, are of insufficient quality, due to the high-temperature effect on raw materials, have a relatively high cost, since the technologies for their production are energy-intensive, while they have an unfavorable effect on the environment.

For the formation of specific properties of finished products, namely high biological value, digestibility, organoleptic characteristics of concentrates, it is advisable to use low processing temperatures (cryotechnology), which maximally preserve the native properties of raw materials $[7,8]$.

The goal of the research is to obtain dry food concentrates from the wastes of processing the seafood that exhibit functional properties. The implementation of this goal is associated with the substantiation, clarification of the technological parameters of cryogenic processing the raw materials of water origin and the study of the quality of the obtained dry seafood concentrates.

\section{Objects and methods of study}

The objects of study were frozen: Pacific herring milt (Pacific herring), octopus skin (Octopus dofleini), scallop mantle (Mizuhopecten yessoensis). Herring milt, octopus skin, scallop mantle were pre-prepared in the process of processing the main raw material. Waste was frozen and stored before use at a temperature not exceeding minus $18^{\circ} \mathrm{C}$ for no more than three months.

Justification of the choice of objects is based on the results of analytical studies of scientific and industrial literature, as well as the data obtained by us empirically.

When cutting an octopus, its skin is formed as a waste (up to $37 \%$ of the mass of raw materials), rich in carotenoids, collagen, taurine, selenium, which can be used for the production of functional cryopowders $[9,10]$. It should also be noted the low level of use of Pacific herring milt for food purposes (up to $12,4 \%$ of the mass of raw materials), generated as waste when cutting the fish. Pacific herring milt contains nucleoproteins, including biologically active substances: deoxyribonucleic acid (DNA) and ribonucleic acid (RNA), as well as polyunsaturated fatty acids of the $\omega 3$ and $\omega 6$ kinds $[11,12]$.

The intensive development of mariculture in the Far East region contributes to an increase in the supply of bivalve molluscs for processing, primarily the coastal scallop, for the production of food products from which motor muscle is used. The scallop mantle, which makes up about $10 \%$ of its mass, is usually not used in its natural form for food purposes, despite the relatively high content of biologically valuable proteins, lipids, carbohydrates, and minerals $[3,4,13,14]$.

Experimental study related to low-temperature exposure to raw materials was carried out in an air freezer with forced air circulation to temperatures in the center of the product of -5 , $-10,-15,-20,-25,-30^{\circ} \mathrm{C}$. To lower temperatures, the raw material was frozen in liquid nitrogen, either by direct immersion in it (Fig. 1a), or by using the liquid nitrogen as a cooling medium for $96 \%$ ethanol, in which raw materials packed in plastic bags were frozen (Fig. 1b ). 


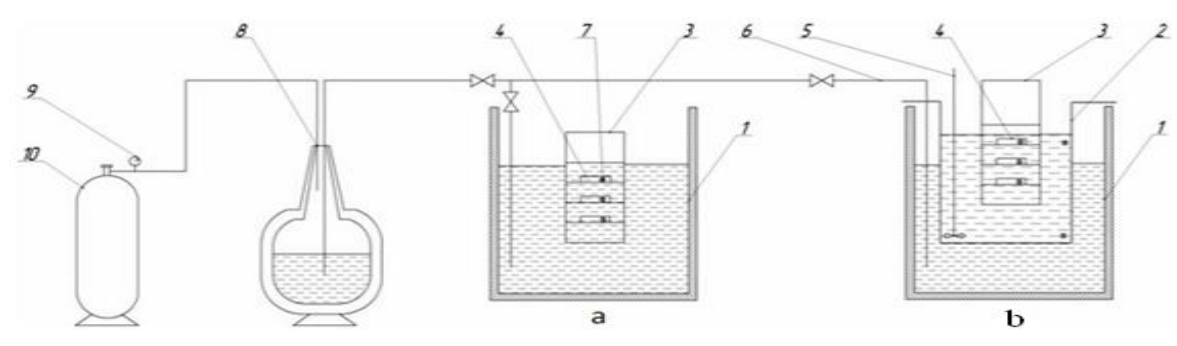

Fig. 1. Liquid nitrogen freezing plant diagram:

1 - container with liquid nitrogen; 2 - container with alcohol; 3 - mesh for the product; 4 - product; 5 stirrer; 6 - liquid nitrogen pipeline; 7 - temperature sensor; 8 - Dewar vessel; 9 - manometer; 10 nitrogen cylinder.

In the process of freezing the raw material, the temperature data were taken in the center of the product, with an electronic thermometer of the Digi-Thermo brand WT-2 with an external temperature sensor, the measurement range was from $-50^{\circ} \mathrm{C}$ to $+300^{\circ} \mathrm{C}$, every minute of the freezing process.

The frozen raw material was crushed on a centrifugal crusher with a double-blade knife, the rotation frequency of the knife shaft was $133,3 \mathrm{sec}^{-1}$, and the processing time was $15 \mathrm{sec}$. Grinding was carried out in a refrigerating chamber at a temperature of $-18^{\circ} \mathrm{C}$ in order to avoid warming the test samples.

A study of the particle size of the raw material ground at different freezing temperatures, as well as the degree of dispersion of the cryopowder, was carried out on an ANALYSETTE22 NanoTec (FRITSCH) laser particle analyzer according to the method attached to the device. This device allows to study particles with a size of $0,01 \ldots 1000 \mu \mathrm{m}$ (i.e., from $10 \mathrm{~nm}$ to $1 \mathrm{~mm}$ ). When working with materials containing larger particles, a sieve analysis technique was used.

The determination of total nitrogen, lipids, minerals, and water was carried out according to the methods generally applied for food products.

The study of the bulk density of dry seafood concentrates was carried out by the volumemass method.

The quantitative determination of carotenoids and the recording of absorption spectra were carried out on a UV-2100 spectrophotometer (Shimadzu, Japan). The spectra of ethanol and hexane extracts were recorded against the corresponding solvents. Oil extracts were diluted with hexane; spectra were recorded against oil diluted with an appropriate amount of hexane.

The content of hexosamines was determined by the spectrophotometric method according to the Pharmacopoeia Article No. 42-1286-99.

To determine the DNA content, we used a method based on extraction and standard hydrolysis of DNA with a $0.5 \mathrm{M}$ solution of perchloric acid to soluble fragments and measurement of ultraviolet absorption at wavelengths of 270 and $290 \mathrm{~nm}$ [15].

The digestibility of protein substances of dry seafood concentrates was determined by the increase in the amount of non-protein nitrogen after treatment of the samples with the proteolytic enzyme pepsin.

Microbiological indicators of dry seafood concentrates - the quality of mesophilic aerobic facultative anaerobic microorganisms (QMAFAnM) and bacteria of the coliforms group (BCG) - were determined in accordance with generally accepted methods for food products.

The biological value of dry concentrates was determined relative to casein. The safety of dry seafood concentrates and their relative biological value (RBV) were studied using the 
method of biological assessment of food products using the ciliated infusoria Tetrahymena pyriformis of the Ciliata class [16].

Statistical processing of the data was carried out by a standard method for evaluating the test results for small samples. The numerical values indicated in the tables and graphs are arithmetic average, the reliability of which $(\mathrm{P})=0,95$, the confidence interval is $(\Delta) \pm 10 \%$.

\section{Results and discussion}

Based on the results of the analysis of technologies for obtaining the cryopowders from vegetable raw materials (berries, fruits, vegetables) $[7,17,18]$, we have proposed a structural technological scheme for the cryoprocessing the seafood in order to produce dry finely dispersed concentrates from them (Fig. 2). In it, in a logical sequence due to the purposefulness of the technological impact, technological operations are structured, the technical and physical parameters of which require verification, clarification and experimental justification.

Raw materials are supplied for processing in frozen form, its temperature is about $-18^{\circ} \mathrm{C}$. The raw material is directed for preliminary grinding into pieces ranging in size from 10 to $30 \mathrm{~mm}$.

An important cryoprocessing process is the preparation of raw materials for dehydration, which is carried out by freeze drying. In our technology, preparation consists in the process of cryogrinding the raw materials. It contributes to the preservation and increase in the concentration of biologically active substances of the initial raw material due to the use of low temperatures during grinding.

A properly carried out cryogrinding process allows to preserve the maximum amount of free and bound water with biologically active substances dissolved in it and practically eliminate their destruction. When freezing, the action of oxidative enzymes is suspended, the processes of aggregation and caramelization of raw materials are prevented, as a result of which the maximum preservation of all nutrients, as well as the natural taste and smell of seafood, is ensured.

With fine grinding, a partial destruction of the cellular structure of the material takes place. It is known that fine grinding has a denaturing effect on protein, which contributes to its better assimilation by the human body [19]. In this regard, we have carried out a number of experiments to determine the rational temperature of the raw material before grinding and the grinding method. The influence of the temperature of the raw material on the particle size after its grinding with use of cutting and impact deformation was investigated (Table 1).

Table 1. Dependence of the particle size of crushed raw materials on the freezing temperature.

\begin{tabular}{|c|c|c|c|}
\hline \multirow{2}{*}{$\begin{array}{c}\text { Temperature in } \\
\text { sample center, }{ }^{\circ} \mathbf{C}\end{array}$} & Perring milt & Scallop mantle & Octopus skin \\
\cline { 2 - 4 } & $3-5$ & $3,5-5,5$ & $4-6,5$ \\
\hline-5 & $1-4$ & $1,5-4,5$ & $1-4,5$ \\
\hline-10 & $0,7-3$ & $1-3,5$ & $1-3,5$ \\
\hline-15 & $0,5-2$ & $0,8-2,0$ & $0,7-2,3$ \\
\hline-20 & $0,3-1,6$ & $0,4-1,5$ & $0,5-2,5$ \\
\hline-25 & $0,08-1,7$ & $0,07-1,9$ & $0,09-2,0$ \\
\hline-30 & $2-10$ & $1-6$ & $2-10$ \\
\hline-40 & $0,01-0,9$ & $0,01-0,8$ & $0,01-0,9$ \\
\hline$-50^{*}$ & $0,01-0,7$ & $2-9$ & $0,01-0,8$ \\
\hline$-100^{*}$ & & \\
\hline
\end{tabular}

* - impact deformation is used

According to the results of the experiments, it can be concluded that the lower the freezing temperature of the raw material, the easier its structure is destroyed during the grinding process. When using devices with cutting deformation, the rational grinding temperature is - 
$30^{\circ} \mathrm{C}$. A mixture of raw fabrics and ice crystals with a particle size of 0,08 to $2,0 \mathrm{~mm}$ is observed. At temperatures above $\left(-25^{\circ} \mathrm{C}\right)$, the particles are larger: from 0,2 to $2,5 \mathrm{~mm}$. At temperatures below $-30^{\circ} \mathrm{C}$, for example $-40^{\circ} \mathrm{C}$, we see an increase in particle sizes up to 1,0 $10,0 \mathrm{~mm}$. Obviously, with such a deep freezing of raw materials, its hardness increases and when using cutting de-formation, the grinding time of $15 \mathrm{sec}$ is not enough to obtain a finely dispersed mixture, and an increase in the duration of the process leads to warming of the product and the appearance of a liquid phase, it becomes plastic and difficult to grind. Thus, it is necessary to freeze the raw material up to a temperature not higher than $-30^{\circ} \mathrm{C}$ and at this temperature cryo-grinding is carried out in apparatuses using cutting destructive deformation of the frozen material with a duration of exposure of 15 seconds. Finer grinding $(0,01-$ $0,9 \mathrm{~mm}$ ) can be achieved by freezing the raw materials to temperatures below subcryohydrate, when the material becomes brittle and easily disintegrates in impact machines (hammer or ball crushers). When crushing by impact de-formation, a constant supply of liquid nitrogen is required to maintain a low temperature of the crushed raw material.

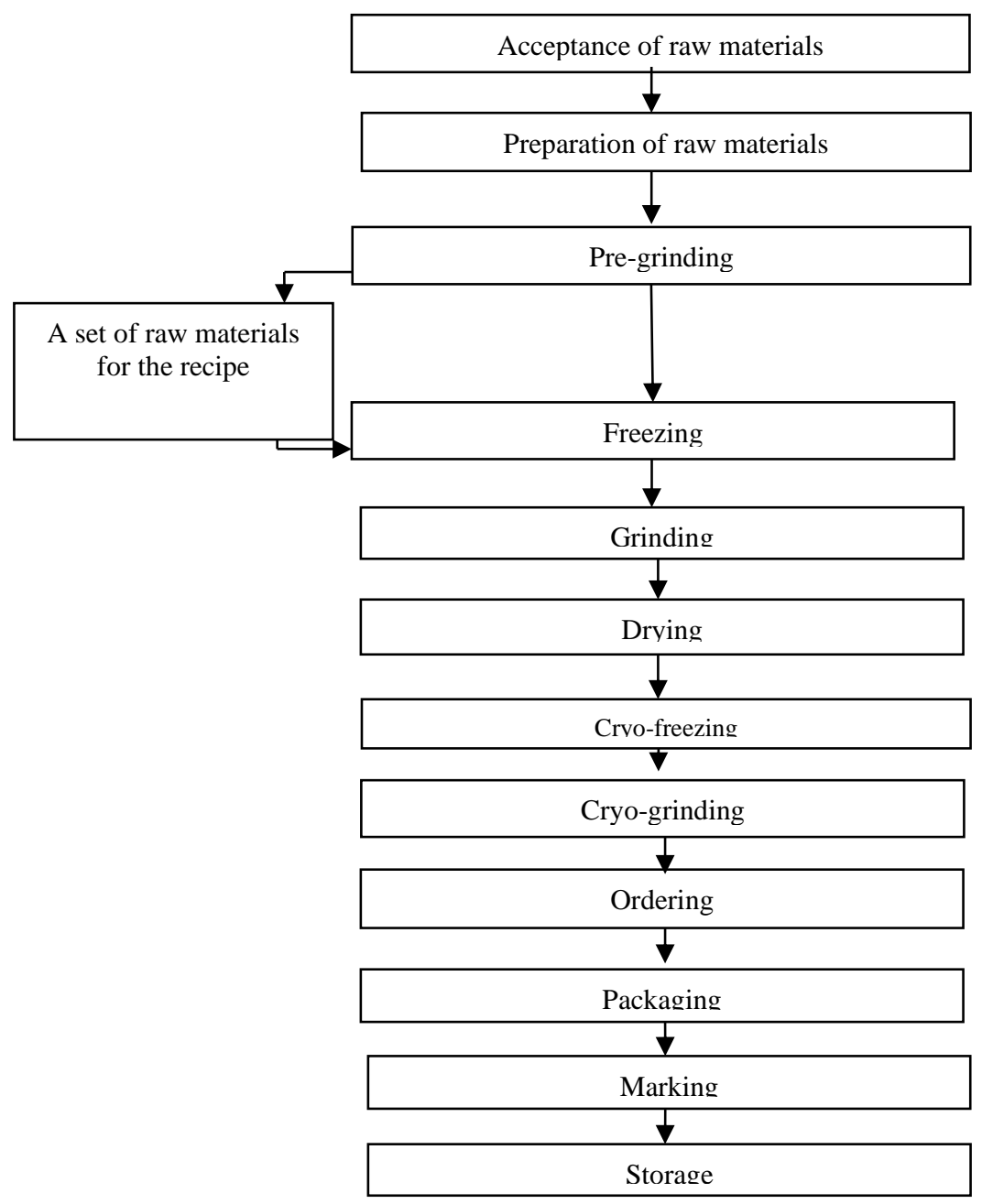

Fig. 2. Block diagram of the technological process for the production of dry food concentrates from seafood 
The resulting frozen finely ground material was directed to freeze drying, which was carried out at a temperature of minus $15-20^{\circ} \mathrm{C}$ under vacuum conditions (pressure 8-9 $\mathrm{Pa}$ ). During sublimation, water in the material in the form of ice passes from a solid state of aggregation to vapor, bypassing the liquid phase. This re-moves $75-90 \%$ of the water. The remaining water evaporates during drying at a temperature of $30-400^{\circ} \mathrm{C}$. The total duration of the process was 16-20 hours. The water content in the concentrates after drying should not exceed $12 \%$.

The dried concentrate was cooled to a temperature of minus $70-$ minus $100^{\circ} \mathrm{C}$ and directed for cryogrinding in order to give it a homogeneous powdery structure, which would be easily absorbed by the human body. It was found that the repeated grinding produces cryopowders with a particle size of $0,3-100$ microns.

The dry seafood concentrates prepared according to the developed technology are creamcolored powders with a brown tint, a pleasant smell and taste characteristic of dry seafood.

Dry food concentrates are freed from a significant part of the water contained in the raw materials, have a high concentration of nutrients and, at the same time, have an insignificant volume and weight. The bulk density of concentrates from octopus skin, herring milt, and scallop mantle is $548,9,387,7$ and $330,7 \mathrm{~kg} / \mathrm{m}^{3}$, respectively.

The yield of dry concentrates when obtaining the experimental samples according to the proposed technological scheme (Fig. 2) was 26,5\% for herring milt, 20,7\% for octopus skin, and $15,4 \%$ for the scallop mantle mass of frozen raw materials. Differences in the yield of dry concentrates were due to the peculiarities of the morphological structure and chemical composition of seafood used as raw materials.

Experimental data on the chemical composition of dry seafood concentrates are in Table 2.

Table 2. Chemical composition of dry seafood concentrates.

\begin{tabular}{|c|c|c|c|}
\hline Indicators, \% & Octopus skin & Herring milt & Scallop mantle \\
\hline Mass fraction of water & $6,2 \pm 0,5$ & $8,2 \pm 0,5$ & $7,1 \pm 0,5$ \\
\hline Mass fraction of protein & $64,4 \pm 0,2$ & $78,7 \pm 0,2$ & $63,9 \pm 0,2$ \\
\hline Mass fraction of lipids & $1,1 \pm 0,5$ & $5,0 \pm 0,5$ & $2,2 \pm 0,5$ \\
\hline $\begin{array}{c}\text { Mass fraction of mineral } \\
\text { substances }\end{array}$ & $22,1 \pm 0,1$ & $8,9 \pm 0,1$ & $16,5 \pm 0,1$ \\
\hline $\begin{array}{c}\text { Mass fraction of } \\
\text { carbohydrates }\end{array}$ & $6,2 \pm 0,2$ & $\operatorname{Tr}$. & $10,3 \pm 0,2$ \\
\hline $\begin{array}{c}\text { Digestibility, non-protein } \\
\text { nitrogen, \% }\end{array}$ & $0,864 \pm 0,02$ & $0,740 \pm 0,02$ & $0,647 \pm 0,02$ \\
\hline
\end{tabular}

Table 2 data demonstrate that dry concentrates are high-protein products: the protein content in them ranges from $63.9 \%$ (scallop mantle) to $78.7 \%$ (herring milt). It is the presence of a large amount of protein substances in seafood concentrates that determines their high functionality. It is important to have a high content of minerals $(8,9-22,1 \%)$ and lipids $(1,1-$ $5,0 \%$ ) in concentrates, which have a positive effect on their functional properties.

The data obtained indicate a different degree of digestibility of proteins in dry concentrates, depending on the type of feedstock. The maximum value was noted for a specimen made of octopus skin. The high degree of digestibility of this concentrate can be explained by the fact that the raw material was thermally processed in the process of its procurement (skinning the octopus), while other types of raw materials were subjected only to freezing.

We determined the content of the main biologically active substances in experimental samples of dry concentrates. The data are in Table 3. 
Table 3. Content of biologically active substances in experimental samples of dry concentrates.

\begin{tabular}{|c|c|c|c|}
\hline Indicators & Octopus skin & Herring milt & Scallop mantle \\
\hline Carotenoids, $\mathrm{mg} / 100 \mathrm{~g}$ & 0,08 & 0,03 & 0,03 \\
\hline Hexosamines, $\%$ & 8,2 & 0,9 & 3,2 \\
\hline DNA, $\%$ & - & 31,7 & - \\
\hline
\end{tabular}

In all samples of concentrates, carotenoids were found, the content of which ranged from 0,03 to $0,8 \mathrm{mg}$ per $100 \mathrm{~g}$ of the product. All samples also contain hexosamines. A high content of hexosamines was noted in samples from the octopus skin $(8,2 \%)$. A rather high DNA content $(31,7 \%)$ was found in the herring milt sample.

Biotesting the dry seafood concentrates shows that they do not demonstrate toxicity, since there was no inhibition of mobility, the presence of death of single individuals, deformation of the cell wall of the ciliates. The obtained results of observations of ciliates in the process of cultivation show a steady increase in the number of cells for 4-5 days in all studied samples. The dynamics of growth in the number of ciliates Tetrahymena pyriformis is shown in Figure 3.

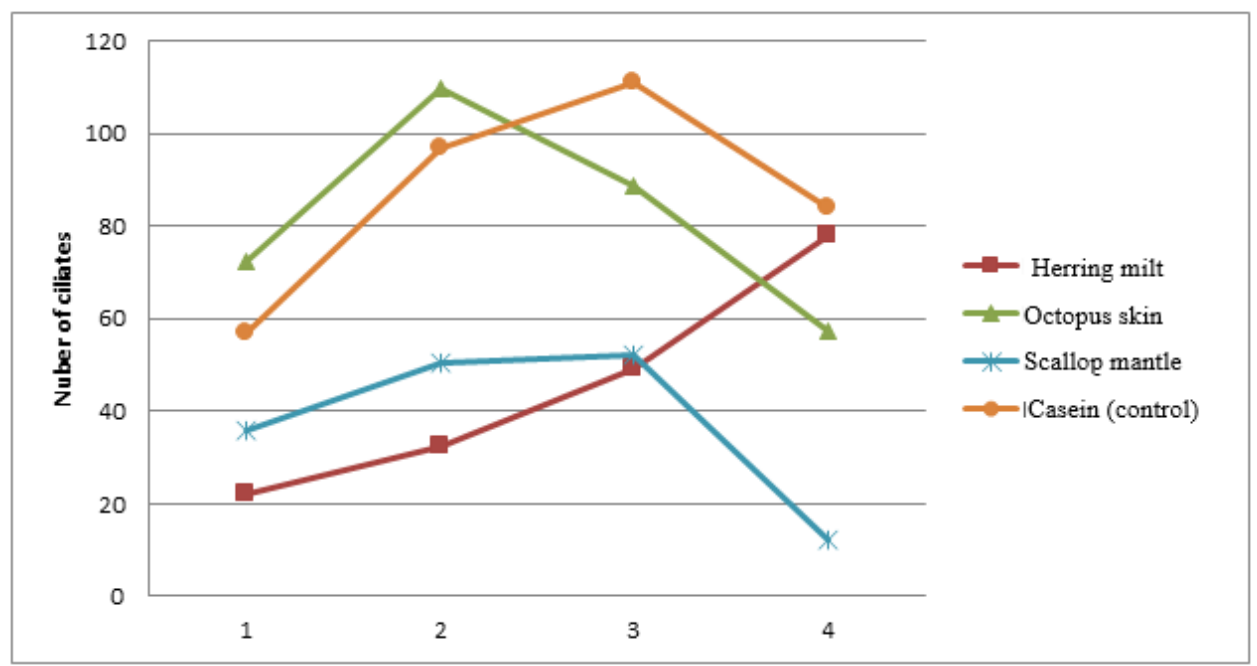

Fig. 3. Dynamics of growth in the number of ciliates Tetrahymena pyriformis on media with the studied samples

The number of ciliates on the third day of studies on octopus concentrates exceeds the values of the control sample and reaches its maximum value on the fourth day, after which a decrease in growth is observed. In the sample from the scallop mantle, a gradual increase in the number of ciliates occurs within five days, similar to that in the control. In a sample from herring milt, a gradual increase in the number of ciliates is observed until the end of the study on the sixth day, when in all other samples, including the control, when this time period is reached, a decrease in the number of cells is noted. In general, the dynamics of the growth of ciliates testifies to the biological safety for human health of the dry seafood concentrates obtained using the developed technology.

The results of experimental studies show a high relative biological value of dry seafood concentrates, while there is a significant difference in values depending on the type of raw material: from $62,3 \%$ for a sample from the scallop mantle to 98,9 for a sample made of octopus skin, which is probably associated with the peculiarities of the chemical composition of the investigated products and the availability of their food components to the enzymes of the ciliates. 
Microbiological indicators are important safety criteria. To characterize dry concentrates, bacteria of the coliforms group (BCG) and QMAFAnM were determined. The results of the studies showed that QMAFAnM is 2,7 $\cdot 103,1,2 \cdot 104$ and 3,2 104 CFU/g in concentrates from octopus skin, scallop mantle, and herring milt, respectively. As for bacteria of the group of intestinal sticks, they were not found in all studied samples.

Thus, the microbiological indicators of the samples of dry seafood concentrates do not exceed the values established by the regulatory documents: QMAFAnM - no more than $5 \cdot 104 \mathrm{CFU} / \mathrm{g}$; BCG - not allowed in the product mass of 1,0 $\mathrm{g}$ [20].

\section{Conclusions and recommendations}

The cryogenic technology of dry food concentrates from wastes from fish and seafood cutting has been improved: Pacific herring milt, octopus skin, scallop mantle. It was found that when grinding the raw materials before freeze drying, it is advisable to reduce its temperature to values close to minus $30^{\circ} \mathrm{C}$. At this temperature and using grinding devices with cutting deformation, a mixture of raw materials and ice crystals with a particle size of 0,08 to 2,0 $\mathrm{mm}$ is obtained. Finer grinding $(0,01-0,9 \mathrm{~mm})$ can be achieved by freezing the raw materials to temperatures below subcryo-hydration, when the material becomes brittle and easily destroyed in impact devices (hammer, ball crushers). When crushing by impact deformation, a constant supply of liquid nitrogen is required to maintain a low temperature of the material being crushed.

The dried concentrate is cooled to a temperature of minus $70-$ minus $100^{\circ} \mathrm{C}$ and subjected to cryo-grinding to a homogeneous powder structure. It was found that the repeated grinding produced cryopowders with a particle size of 0,3 - 100 microns.

Dry concentrates from the wastes of commercial hydrobionts are classified as highprotein products, which allows them to be classified as natural food biocorrectors. It should be noted the rather high degree of digestibility of protein concentrates. It is important to have a high content of mineral substances in concentrates, as well as lipids, which have a positive effect on their functional properties. The study of the content of biologically active substances showed that carotenoids and hexosamines were found in all samples of concentrates, their high content was noted in a sample from the octopus skin. A high DNA content $(31,7 \%)$ was found in the concentrate from herring milt.

Biotesting the dry seafood concentrates shows that they do not demonstrate toxicity and have a fairly high relative biological value.

Thus, dry concentrates obtained from fish and seafood processing wastes using the cryogenic technology exhibit high functionality and can be recommended for use in the preparation of instant products or in the form of food biocorrectors in order to balance it in terms of micro- and macronutrients, of high quality and biological usefulness.

\section{References}

1. O. Ya. Mezenova, Prospects for obtaining and using the proteins from secondary fish raw materials // Bulletin of the International Academy of Cold. 2018. No. 1. P. 5 - 10.

2. O.V. Tabakaeva, Tabakaev A.V., Lukoshko V.G. New directions of use of bivalve mollusks of the Far Eastern region // Food Industry, No. 4, 2016. P. 19 - 23.

3. E.V. Maslennikova, Cherevach E.I., Yudina T.P., Babin Yu.V., Tsibulko E.I. Protein hydrolysis technology from the scallop mantle. // Food industry, No. 5, 2009. P. 18 - 19.

4. L.Yu. Lazhentseva, Likhacheva E.V. Technology of new protein products from Far Eastern bivalve molluscs. // Bulletin of Universities. Food technology, No. 5-6, 2008. P. $63-65$. 
5. O.V. Tabakaev, Tabakaev A.V. Nutritional and biological value of food parts of the commercial bivalve mollusk Anadara broughtoni // Nutrition issues. Vol. 84, No. 4, 2015. P. 112 - 118.

6. O.Ya. Mezenova, Heling A., Merzel T. Biopotential of secondary fish raw materials // Bulletin of Universities. Food technology, No.1, 2018. P. 11-15.

7. A.B. Lisitsin, Chernukha I.M., Lunina O.I. Current trends in the development of the functional food industry in Russia and abroad. Theory and practice of meat processing. - 2018. - Vol. 3(1). - P. 29-45. DOI: https://doi.org/10.21323/2414-438X-2018-3-1-2945

8. G.I. Kasyanov, Lomachinskii V.V., Akhmedov M.E., Ramazanov A.M., Yaralieva Z.A. Obtaining and application of biocorrectors in the form of cryopowders from vegetables and fruits. Science. Technics. Technology. 2014. No.3. P.117-123.

9. A.A. Zyuzgina, Kupina N.M. Chemical composition and technological characteristics of the Japanese sea octopuses. TINRO Bulletin. 2005. V.142. P.323-329.

10. N. Souissi, Jridi, M., Nasri, R. [et al.] Effects of the edible cuttlefish gelatin on textural, sensorial and physicochemical quality of octopus sausage.LWT - Food Science and Technology-2016. - Vol. 65. - P. 18-24. DOI: https://doi.org/10.1016/j.lwt.2015.07.051

11. N.V. Demetyeva, Bogdanov V.D. Pacific herring milt pudding technology. MSTU Bulletin. - 2016.- V.19. - No.3.- P.610-616.

12. R. Durand, E. Fraboulet, A. Marette, L. Bazinet Simultaneous double cationic and anionic molecule separation from herring milt hydrolysate and impact on resulting fraction bioactivities. Separation and Purification Technology. 2019. V. 210. P. 431-441. DOI: https://doi.org/10.1016/j.seppur.2018.08.017

13. O.V. Tabakaeva, Tabakaev A.V. Tissue carotenoid composition of the Far-East bivalve mollusk Anadara broughtonii. Chemistry of Natural Compounds. - 2015. - Vol. 51(6). - P. 1171-1173. DOI: https://doi.org/10.1007/s10600-015-1522-2

14. J-R. Han, Han J-N., Sun S-G. [et al.]. Characteristic antioxidant activity and comprehensive flavor compound profile of scallop (Chlamys farreri) mantle hydrolysates-ribose Maillard reaction products. / Food Chemistry - 2018. - Vol. 261. P. 337-347. DOI: https://doi.org/10.1016/j.foodchem.2018.04.044

15. S.E. Severin, Solovieva G.A. Biochemistry Workshop. - Moscow: MSU, 1989. - 163 p

16. V.D. Bogdanov, Sakharova O.V., Sakharova T.G. Study of the safety and biological value of dry sea cucumber concentrate by biotesting. Scientific Journal of Dalrybvtuz. 2016. V.37. P.93-98.

17. V.A. Voskoboinikov, Basic production methods for ystant products. Food industry.2015. No.7. P.21-23.

18. R. Pavlyuk, Kakadii I., Pogarskii A., Stukonozhenko. The influence of the processes of para-thermal cryogenic treatment and mehanolysis on biopolymers and biologically active substances in the process of producing the health containing nanoproducts. Eastern-European journal of enterprise technologies. 2017. V.6. No.11(90) P.41-47.

19. I.A. Rogov, Babakin B.S., Fatykhov Yu.A. Cryoseparation of raw materials of biological origin. -Monograph. Ryazan: Our time. - 2005. - 288 p.

20. Technical Regulations of the Eurasian Economic Union TR EAEU 040/2016 "On the safety of fish and fish products" 